\title{
Custom-designed mouthpiece for HDR brachytherapy of embryonal rhabdomyosarcoma of the soft palate
}

\author{
Emmanuel Ekwelundu, PhD, Matthew J. Krasin, MD, Jonathan B. Farr, PhD \\ Department of Radiological Sciences, Division of Radiation Oncology, St. Jude Children's Research Hospital, Memphis, TN, USA
}

\begin{abstract}
This paper describes the design and fabrication of the mouthpiece used for high-dose-rate (HDR) brachytherapy of a cancerous lesion in the soft palate of a pediatric patient. A custom mouth guard made with Thermo-forming material (Clear - Mouthguard) similar to those used by athletes, with a bite section, alveolar sulcus, hard and soft palate sections was made. Markers were placed around the lesion using a color transfer applicator and the impression transferred to the mouthpiece. Ten catheters arranged in a plane were placed on the inferior side (concave part) of the mouthpiece, and held in place by stitching each to the mouthpiece. Two pieces of lead $(\mathrm{Pb})$ sheets with total thickness of $5.7 \mathrm{~mm}$ were placed beneath the catheters. Wax was used to create additional distance between the tongue and the catheters, and the entire assembly was covered with wax.
\end{abstract}

Key words: HDR brachytherapy, mouthpiece, rhabdomyosarcoma, soft palate.

\section{Purpose}

Rhabdomyosarcoma is a cancer thought to arise from skeletal muscle progenitor cells; it is the most common type of soft tissue sarcoma in children. Rhabdomyosarcoma accounts for about $3 \%$ of all childhood cancers. Embryonal rhabdomyosarcoma, as opposed to alveolar rhabdomyosarcoma, is the most common type of rhabdomyosarcoma that usually affects infants and young children. These cancers tend to occur in the head and neck area, bladder, vagina, in and around the prostate and testicles.

Treatment of this disease involves surgery, chemotherapy, radiation therapy, and combination therapy. Radiation therapy to the soft palate using external beams will give extraneous dose to the surrounding structures. Late effects associated with this technique include severe fibroses of surrounding normal tissues, asymmetric facial growth, zerostomia, trismus, mandibular osteoradionecrosis, and visual and dental abnormalities. Another unwanted long term result is the small but increased risk of secondary cancer induction [1]. Intensity-modulated radiation therapy (IMRT) has been extensively used for the treatment of soft tissue sarcoma and reports indicate excellent local control can be achieved while minimizing late effects [2-13]. Intensity-modulated radiation therapy has been shown to achieve better sparing of normal structures than conventional 2D planning or 3D conformal planning techniques $[4,9]$. Proton therapy has been reported for the treatment of soft tissue sarcomas [14-16]. Substantial normal tissue sparing was observed with proton therapy dose distributions compared to either three-dimensional conformal radiation therapy (3DCRT) or IMRT plans.

Brachytherapy has also been routinely used for the treatment of rhabdomyosarcoma [17-22]. The overall survival is similar to that reported for external beam irradiation without the severe fibrosis and asymmetric growth problems. Given these reports in the literature on differing methods to treat rhabdomyosarcoma, an opportunity was identified to make a brachytherapy applicator that was less invasive than interstitial brachytherapy, yet permitted pre-implant imaging and treatment planning. In this manner, the dosimetric advantages of brachytherapy over external-beam methods could be utilized while being practical for use on pediatric patients. To our knowledge, there are no other reports in the literature on the use of such applicator in the pediatric population.

\section{Material and methods}

A custom designed mouthpiece was designed and included the following components: a clear mouthguard, 4 French catheters, a lead shield, and wax material. The dental hygienist, having selected the correct size of the bite impression tray, made a dental impression of the patient that includes the teeth, alveolar sulcus, hard and 
soft palate. Using a color transfer applicator, the radiation oncologist delineated the surgical margins on the soft palate and these in turn transferred to dental impression. Dental stone was subsequently poured into the dental impression and allowed to set. Figure 1 shows the positive impression of the patient's mouth with the surgical margins imprinted on the mold.

Thermo-Forming Material (Clear - Mouthguard, Henry Schein Company, Melville, NY, USA), $3.8 \mathrm{~mm}$ thick with a density of approximately $1.007 \mathrm{~g} / \mathrm{cm}^{3}$, was heated until it became soft, then formed around the teeth model (Fig. 2). This resulted in the mouthguard thickness of about $2.5 \mathrm{~mm}$. Next, ten catheters were sewn into a single plane into the mouthguard with about $2 \mathrm{~mm}$ extending distally beyond the mouthpiece (Fig. 3).

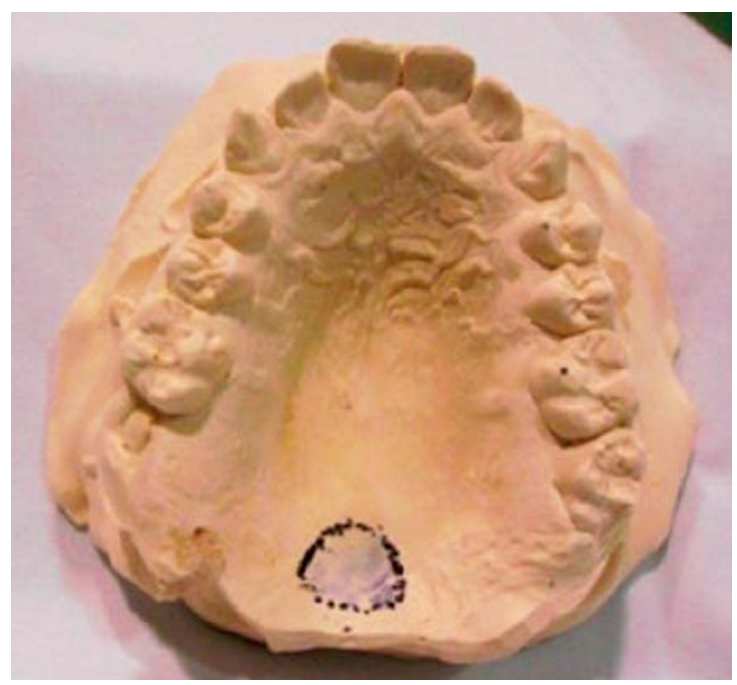

Fig. 1. Positive dental impression with surgical margins delineated

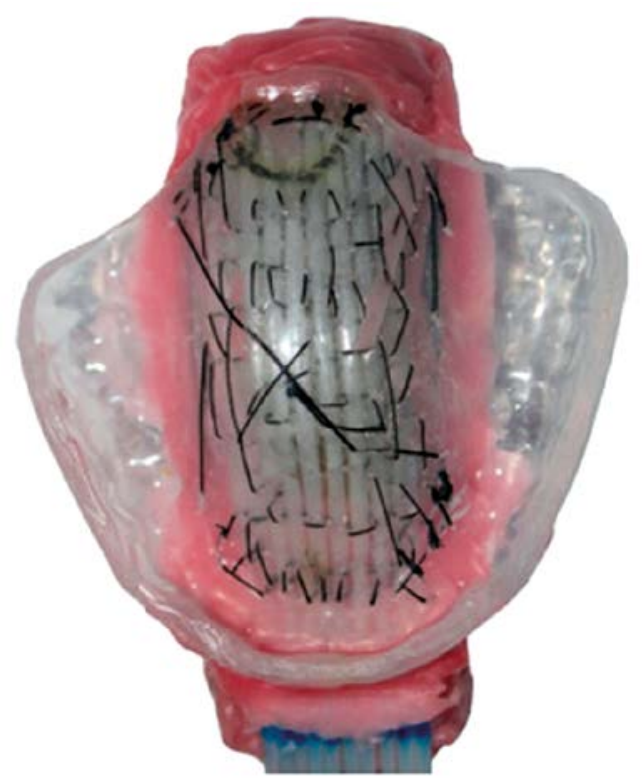

Fig. 3. Mouthpiece view showing stitching of catheters to the Clear-Mouthguard
Two layers of lead, total thickness of $5.7 \mathrm{~mm}$, were fashioned to fit the concave part of the mouthpiece and placed over the catheters, and extended about $5 \mathrm{~mm}$ beyond the ends of the catheters. The easily pliable lead pieces were held in place by also stitching them to the mouthpiece. The ${ }^{192} \mathrm{Ir}$ half-value layer (HVL) of lead is $2.5 \mathrm{~mm}$ [23], and the above lead thickness will give approximately $21 \%$ transmission of the dose to the underside of the mouthpiece. To further extend the distance between the catheters and the tongue, $20 \mathrm{~mm}$ of wax was used to fill the concave part of the mouthpiece, thereby holding the various components together as one piece (Fig. 4).

Prior to using the mouthpiece by the patient, the entire assembly was wrapped with saran-wrap. The patient, a 15 year old football player, tolerated the mouthpiece

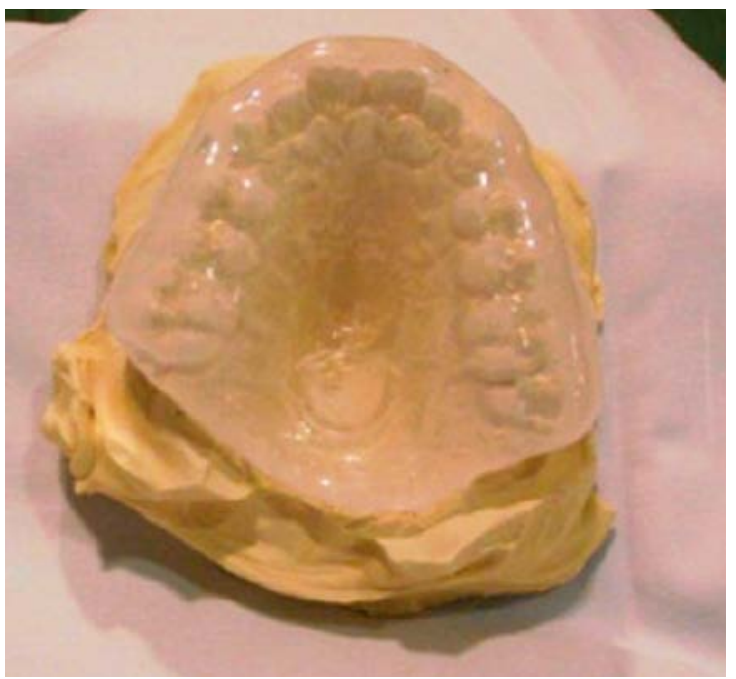

Fig. 2. Clear-Mouthguard superimposed on the positive dental impression

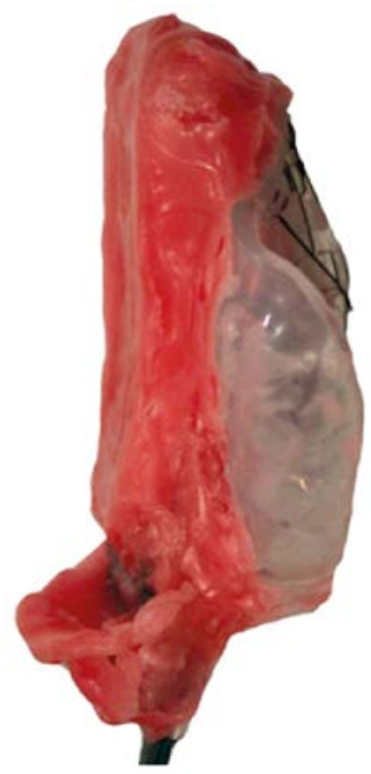

Fig. 4. Mouthpiece view showing the thickness of wax used 


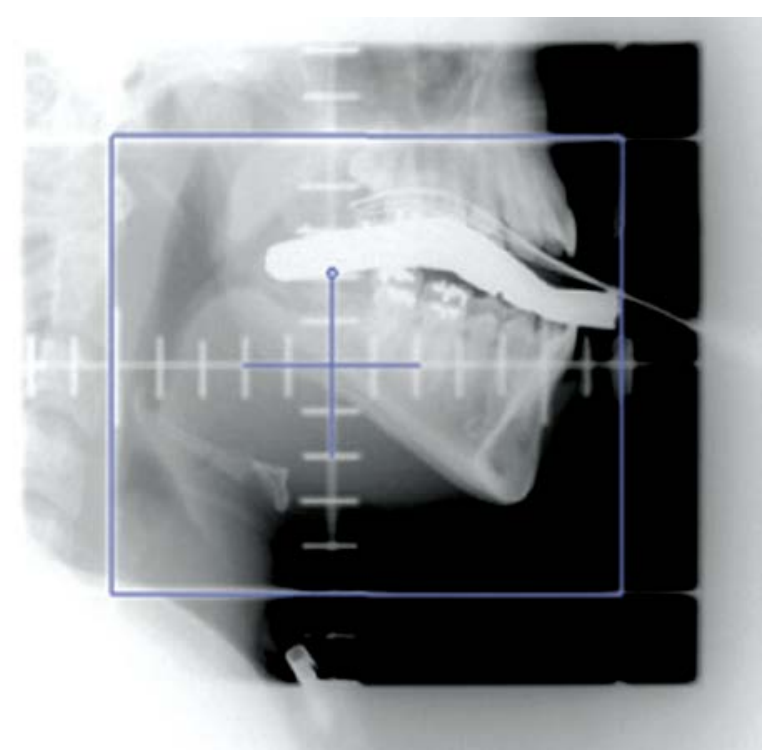

Fig. 5. Fluoro verification of mouthpiece placement

very well and had no gagging reflex. The positioning of the mouthpiece inside the patient was verified with a Nucletron Fluoro simulator located in the same high-doserate (HDR) suite (Fig. 5).

Using a second mouthpiece similar in shape and size as the first mouthpiece, but with the lead shield re- placed with a thermoplastic bolus of the same thickness, the supine patient received a CT scan with $3 \mathrm{~mm}$ slice thickness. Clinical target volumes (CTV) was delineated by the radiation oncologist and treatment planning was completed using Oncentra Treatment Planning System (TPS) v.4.3. Only a few dwell positions around the tip of the catheters were activated since the CTV is located towards the end of the catheters. A total dose of 36.0 Gy was prescribed at 2.0 Gy daily dose to a lesion depth of $5 \mathrm{~mm}$. The total treatment time was 66.5 seconds for fraction one with the Nucletron microSelectron HDR ${ }^{192}$ Ir brachytherapy source $\left(21.95 \mathrm{mGym}^{2} \mathrm{~h}^{-1}\right.$ or $\left.5.4 \mathrm{Ci}\right)$.

To evaluate the delivered dose, optically stimulated luminescent dosimeters (OSLDs) were fastened in vivo to the mouthpiece to measure doses to the tongue and the soft palate surface at locations determined by the TPS to be maximum dose. The OSLDs were mailed to Landauer Special Dosimetry Services for readout.

\section{Results}

Figure 6 shows the axial, sagittal, and coronal views through the CTV with 2.0 and 3.0 Gy isodose lines displayed. It also shows the DVH for CTV and the organsat-risk (i.e., right and left mandibles). OSLD report shows that the dose to the soft palate surface was $3.65 \mathrm{~Gy}$, consistent with the 3.75 Gy TPS result. The dose to the tongue as measured with OSLD was 0.308 Gy compared to the 0.28 Gy TPS result.

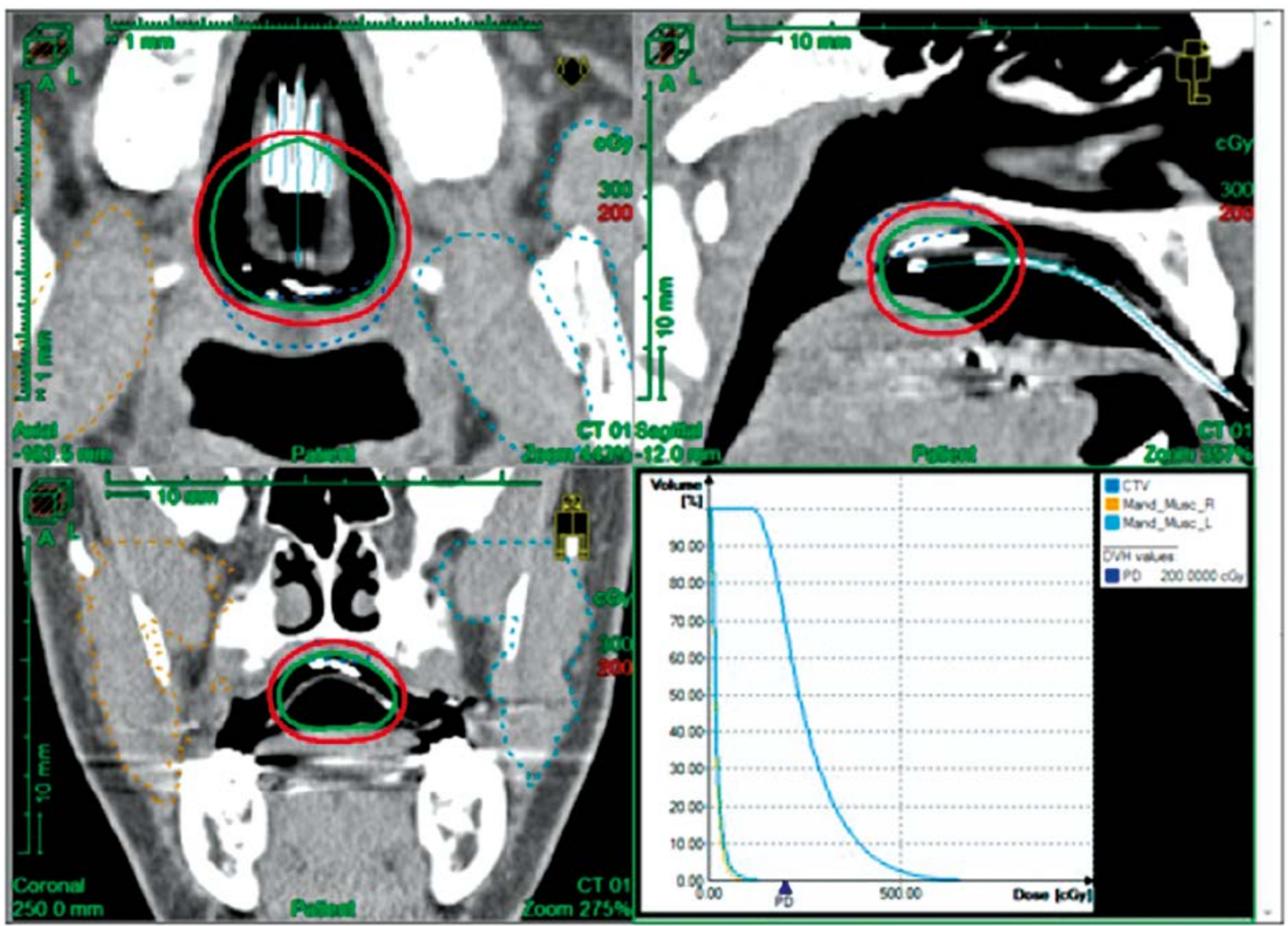

Fig. 6. Axial, sagittal, and coronal views through the CTV and the DVH 


\section{Discussion}

The patient's soft palate lesion was surgically resected and pathology report confirmed embryonal rhabdomyosarcoma with no metastasis. Subsequently, he received three cycles of chemotherapy prior to this radiation component of local control. The primary reason for using brachytherapy was to reduce dose to normal tissues while providing a conformal therapeutic dose. However, one of the late effects of using brachytherapy for STS is trismus and osteonecrosis [20]. Ulcerations around the hard palate were noted at fraction number ten, and this was resolved by giving the patient a nine-day treatment break. The measured doses using OSLDs were within $0.1 \mathrm{~Gy}$ of the dose calculated by the TPS results for a given treatment fraction. This level of agreement was considered good given the differences in OSLD calibration (i.e., using ${ }^{60} \mathrm{Co}$, whereas the treatment used ${ }^{192} \mathrm{Ir}$ ), prediction of lead attenuation, and differences in radiation scatter conditions between that assumed in the TPS and that present during the patient treatment [24].

\section{Acknowledgements}

We wish to express our gratitude to Diana Hill with St. Jude Children's Research Hospital Dental Clinic; David Sobczak, our linear accelerator engineer, for assembling the mouthpiece, and all the therapists involved with this patient's treatment. Additionally, we wish to thank Dr. Mark Rivard for painstakingly reviewing the manuscript.

\section{Disclosure}

Authors report no conflict of interest.

\section{References}

1. Raney RB, Asmar L, Vassilopoulou-Sellin R et al. Late complications of therapy in 213 children with localized, nonorbital soft-tissue sarcoma of the head and neck: a descriptive report from the Intergroup Rhabdomyosarcoma Studies (IRS)-II and -III. Med Pediatr Oncol 1999; 33: 362-371.

2. Münter MW, Karger CP, Hoffner SG et al. Evaluation of salivary gland function after treatment of head-and-neck tumors with intensity-modulated radiotherapy by quantitative pertechnetate scintigraphy. Int J Radiat Oncol Biol Phys 2004; 58: 175-184.

3. McDonald MW, Esiashvili N, George BA et al. Intensitymodulated radiotherapy with use of cone-down boost for pediatric head and neck rhabdomyosarcoma. Int J Radiat Oncol Biol Phys 2008; 72: 884-891.

4. Chan MF, Schupak K, Burman C et al. Comparison of intensity-modulated radiotherapy with three dimensional conformal radiation therapy planning for glioblastoma multiforme. Med Dosim 2003; 28: 261-265.

5. Puri DR, Wexler LH, Meyers PA et al. The challenging role of radiation therapy for very young children with rhabdomyosarcoma. Int J Radiat Oncol Biol Phys 2006; 65: 1177-1184.

6. Sterzing F, Stoiber EM, Nill S et al. Intensity modulated radiotherapy (IMRT) in the treatment of children and adolescents - a single institution's experience and a review of literature. Radiat Oncol 2009; 4: 37.

7. Combs SE, Behnisch W, Kulozik AE et al. Intensity modulated radiotherapy (IMRT) and fractionated stereotactic radiotherapy (FSRT) for children with head-and-neck-rhabdomyosarcoma. BMC Cancer 2007; 7: 177.
8. Hua C, Gray JM, Merchant TE et al. Treatment planning and delivery of external beam radiotherapy for pediatric sarcoma: The St. Jude Children's Research Hospital experience. Int J Radiat Oncol Biol Phys 2008; 70: 1598-1606.

9. Kam MKM, Chau RMC, Suen J et al. Intensity-modulated radiotherapy in nasopharyngeal carcinoma: Dosimetric advantage over conventional plans and feasibility of dose escalation. Int J Radiat Oncol Biol Phys 2003; 56: 145-157.

10. Xia P, Fu KK, Wong GW et al. Comparison of treatment plans involving intensity modulated radiotherapy for nasopharyngeal carcinoma. Int J Radiat Oncol Biol Phys 2000; 48: 329-337.

11. Hein PA, Gladstone DJ, Bellerive MR et al. Importance of protocol target definition on the ability to spare normal tissue: An IMRT and 3D-CRT planning comparison for intraorbital tumors. Int J Radiat Oncol Biol Phys 2005; 62: 1540-1548.

12. Kam MK, Leung SF, Zee B et al. Impact of intensity-modulated radiotherapy (IMRT) on salivary gland function in early-stage nasopharyngeal carcinoma (NPC) patients: A prospective randomized study [Abstract]. Proc Am Soc Clin Oncol 2005; 23 (Suppl. 16S): 5501.

13. Lee NY, de Arruda FF, Puri DR et al. A comparison of intensity-modulated radiation therapy and concomitant boost radiotherapy in the setting of concurrent chemotherapy for locally advanced oropharyngeal carcinoma. Int J Radiat Oncol Biol Phys 2006; 66: 966-974.

14. Hug EB, Adams J, Fitzek M et al. Fractionated, three-dimensional, planning-assisted proton-radiation therapy for orbital rhabdomyosarcoma: A novel technique. Int J Radiat Oncol Biol Phys 2000; 47: 979-984.

15. Yock T, Schneider R, Friedmann A et al. Proton radiotherapy for orbital rhabdomyosarcoma: Clinical outcome and a dosimetric comparison with photons. Int J Radiat Oncol Biol Phys 2005; 63: 1161-1168.

16. Kozak KR, Adams J, Krejcarek SJ et al. A dosimetric comparison of proton and intensity-modulated photon radiotherapy for pediatric parameningeal rhabdomyosarcoma. Int J Radiat Oncol Biol Phys 2009; 74: 179-186.

17. Blank LECM, Koedooder K, van der Grient HNB et al. Brachytherapy as part of the multidisciplinary treatment of childhood rhabdomyosarcoma of the orbit. Int J Radiat Oncol Biol Phys 2010; 77: 1463-1469.

18. Dal Maso M, Kushner JH, Dedo HH. Rhabdomyosarcoma of the soft palate in three patients with follow-up of longer than ten years. Head and Neck Surgery 1986; 9: 46-50.

19. Esche BA, Haie CM, Gerbaulet AP et al. Interstitial and external radiotherapy in carcinoma of the soft palate and uvula. Int J Radiat Oncol Biol Phys 1988; 15: 619-625.

20. Nag S, Tippin D, Ruymann FB. Long-term morbidity in children treated with fractionated high-dose-rate brachytherapy for soft tissue sarcomas. J Pediat Hemat Oncol 2003; 25: 448-452.

21. Viani GA, Novaes PE, Jacinto AA et al. High-dose-rate brachytherapy for soft tissue sarcoma in children: A single institution experience. Radiat Oncol 2008; 3: 9.

22. Healey EA, Shamberger RC, Grier HE et al. A 10-year experience of pediatric brachytherapy. Int J Radiat Oncol Biol Phys 1995; 32: 451-455.

23. Khan FM. The Physics of Radiation Therapy. Williams \& Wilkins, Baltimore 1984; p. 355.

24. Thomadsen BR, Williamson JF, Rivard MJ et al. Anniversary Paper: Past and current issues, and trends in brachytherapy physics. Med Phys 2008; 35: 4708-4723. 